\title{
Da interpretação de Gilberto Freyre e Roberto Damatta sobre a formação moderna da sociedade brasileira à crítica sociológica de Jesse de Souza
}

\author{
Submetido em: 04/11/2019, aprovado em: 10/12/2020 \\ 10.30612/mvt.v7i13.10637 \\ João Gustavo Jara Russo ${ }^{1}$ \\ Wellington dos Santos ${ }^{2}$
}

\begin{abstract}
RESUMO: Este estudo aborda os aspectos acerca da problematização do conceito de "identidade nacional" e "formação social" na obra Casa Grande \& Senzala de Gilberto Freyre utilizando este como "ponte metodológica" para expor as leituras críticas do sociólogo Jessé de Souza em relação às "teorias culturalistas": paradigma das ciências sociais, de acordo com este autor, onde categorias-analíticas pré-modernas como "personalismo" e "patrimonialismo" atualizadas, por exemplo, pelo antropólogo social Roberto DaMatta são apresentadas como ferramentas interpretativas para se pensar o Brasil contemporâneo. Ao reunir e comparar os principais textos dos autores sobre a questão "modernização" (Carnavais, malandros e heróis de DaMatta e A modernização seletiva de Jessé), por meio de revisão bibliográfica, indica-se que instituiçôes como Estado, sociedade civil e mercado não podem ser confundidas ou dominadas pelo "capital social de relaçóes pessoais", mas sim entendidas como campos de interesses sociais.
\end{abstract}

Palavras-chave: Casa Grande \& Senzala, Teorias culturalistas, Jessé de Souza.

\section{From the interpretation of Gilberto Freyre and Roberto Damatta on the modern formation of brazilian society to the sociological criticism of Jesse de Souza}

ABSTRACT: This study approaches the aspects about the problematization of the concept of "national identity" and "social formation" in Gilberto Freyre's Casa Grande \& Senzala, using this as a "methodological bridge" to expose the critical readings of sociologist Jessé de Souza in relation to

1 Graduado em Direito e Mestre em Sociologia pelo programa de pós-graduaçáo em sociologia da Universidade Federal da Grande Dourados (UFGD). Email: (joao.gustavo_jr@hotmail.com).

2 Graduado em Filosofia e mestrando do programa de pós-graduação em Filosofia (PROFILO) da Universidade Federal de Mato Grosso do Sul (UFMS). Tem experiência como docente na Educação Básica e Técnica, nas modalidades presencial e à distância. Email: (weellingt@hotmail.com). 
to "culturalist theories": social science paradigm where pre-modern analytic categories such as "personalism" and "patrimonialism", for example, updated by social anthropologist Roberto DaMatta are presented as tools for thinking about contemporary Brazil. By gathering and comparing the authors' main texts on the issue of "modernization" (DaMatta's Carnivals, Tricksters, and Heroes and The Selective Modernization of Jesse), it is pointed out that institutions such as the State, civil society, and the market are not. they can be confused or dominated by the "social capital of personal relations", but understood as fields of social interest.

Keywords: Casa Grande \& Senzala, Culturalist Theories, Jessé de Souza.

\section{De la interpretación de Gilberto Freyre y Roberto Damatta sobre la formación moderna de la sociedad brasileña a la crítica sociológica de Jesse de Souza}

RESUMEN: Este estudio aborda aspectos sobre la problematización del concepto de "identidad nacional" y "formación social” en la obra Casa Grande \& Senzala de Gilberto Freyre utilizando este como un "puente metodológico" para exponer las lecturas críticas del sociólogo Jessé de Souza en relación a las "teorías culturalistas": paradigma de las ciencias sociales donde categorías analíticas premodernas como "personalismo" y "patrimonialismo", por ejemplo, actualizadas por el antropólogo social Roberto DaMatta, se presentan como herramientas para pensar el Brasil contemporáneo. Al recopilar y comparar los principales textos de los autores sobre la cuestión de la "modernización" (Carnavales, bribones y héroes de DaMatta y La modernización selectiva de Jessé), mediante revisión bibliográfica, se indica que instituciones como el Estado, la sociedad civil y el mercado no pueden ser confundidos o dominados por el "capital social de las relaciones personales", sino más bien entendidos como campos de intereses sociales.

Palabras clave: Casa Grande y Senzala, teorías culturalistas, Jessé de Souza.

\section{INTRODUÇÃO}

Na republicação do escrito a Subcidadania brasileira (2018) o sociólogo brasileiro Jessé de Souza (1960-atualmente) esclarece na Introdução desta obra que tanto neste quanto no livro $A$ modernização seletiva (2000) se interessou em realizar a primeira crítica sistemática ao que chamou 'culturalismo conservador'; isto é: leitura e avaliação direcionada à interpretação liberal e dominante - a seu ver, do processo de modernização da sociedade brasileira. Jessé busca, especificamente, problematizar "as causas" de nossa abissal desigualdade social e por que esta questão constituiu-se secundária historicamente pela interpretação da "corrupçáo patrimonialista" enraizada em nossas instituiçôes como suposto problema fundamental.

Desse modo, o autor pretende "reconstruir" as bases de uma verdadeira teoria sociológica crítica sobre o Brasil moderno. Partindo, assim, da análise científica de três objetos de investigação presentes 
em seus escritos ${ }^{3}$ : 1) a desigualdade social brasileira, 2) tal leitura dominante do patrimonialismo como principal problema sócio-político brasileiro, 3) e a implicação de situação de classe da "ralé" (ou subcidadania) brasileira na luta social por recursos escassos na sociedade capitalista.

Ou seja, a proposta deste artigo é elucidar uma "interpretação alternativa do dilema brasileiro" abordando a implicação teórica de concepçóes acadêmicas que retratam determinado "mal de origem" na formação social do Brasil desde a colônia como explicação para as principais questôes sociais hoje. Veremos que Gilberto Freyre (1900-1987) é o fundador dessa corrente hegemônica; seguido e re-interpretado por Sérgio Buarque de Holanda (1902-1982) e contemporaneamente Roberto DaMatta (1936-atualmente).

Pode-se dizer que a sociologia de Jessé de Souza baseia-se num estudo analítico entre a relação indivíduo e sociedade; de diagnóstico conceitual entre "dinâmicas institucionais" (especialmente "familiar") e o problema da "estratificação social" demonstrando a influência do "capital cultural" (valores artísticos, científicos e filosóficos) na formação/reprodução de "divisões de classes" na sociedade brasileira.

Da aproximação entre Jessé de Souza e Roberto DaMatta pelo recorte "modernidade", indica-se a importância das ciências sociais interpretar "Estado, mercado e sociedade civil" como unidades funcionais interdependentes para a vida social, cujo entendimento e reconhecimento institucional não pode ser analisado pelo "capital social de relaçôes pessoais" como faz a abordagem antropológica damattiana.

O resultado dessa leitura investigativa-comparativa sugere a problematização de uma "modernização estrutural seletiva" da sociedade brasileira e a construção da subcidadania (ou provocativamente: a ralé): envolvendo para Jessé de Souza a indagação do que é "ser gente" no Brasil; isto é, conclui-se que o empecilho de desenvolvimento da sociedade brasileira diz respeito à "formação e reprodução" da desigualdade social.

Por isso a sociologia crítica de Jessé de Souza parti literalmente do berço, isto é, da socialização familiar primária, para que se compreenda as precondiçóes sociais, morais e culturais exigidas em sociedades modernas-complexas e como elas irão definir todas as chances relativas de cada um de nós na formação da personalidade individual e na competição social por recursos escassos. Contudo, espera-se com este estudo contribuir para a possibilidade de futuras pesquisas sobre tal assunto dado sua pertinência e sensibilidade conceitual-empírica.

\section{NOTA PRELIMINAR}

Entender e descrever o brasileiro como povo da alegria, do calor humano, da hospitalidade e do sexo, para Jessé (2009, p. 29) - é falar, antes de tudo, num tipo de mito nacional até certo ponto necessário, construído por excelência para a produção de um sentimento moral e espiritual - aliás, característica de todo mito: de pertencimento, intersubjetividade e solidariedade coletiva: desse modo, falar em "identidade nacional é uma espécie de mito moderno".

Como elucida Ortiz (2006, p. 8) a noção de identidade-nacional é "uma construçáo simbólica" que se remete a pluralidade, etnia, regionalidade, crença, saberes ou valores considerando diferentes

3 A ralé brasileira: quem é e como vive (2009), A tolice da inteligência brasileira (2015) e A elite do atraso: da escravidão à Lava Jato (2017). 
grupos sociais e momentos históricos. Já o antropólogo social Roberto DaMatta (1994, p. 16) ressalta que cada sociedade se utiliza "de um número limitado de 'coisas' (e de experiências) para construir-se como algo único", singular: no caso brasileiro, a evidente paixão por futebol, comida caseira, música popular ou carnaval compóe relativamente o "ser brasileiro".

Nas palavras desse autor, "se você descobrir como as pessoas se posicionam em face de uma lista de coisas importantes, você fará um inventário de identidades sociais e de sociedades, o que lhe permitirá descobrir o estilo e o 'jeito’ de cada sistema” (DAMATTA, 2004, p. 10). E continua,

É que o Brasil tem que ser lido de modo complementar: tanto pelos números e pelo seu lado "moderno", quanto por suas instituiçóes e pelo seu lado mais sensível e qualitativo. Sustento que, para entender bem o Brasil, temos que discuti-lo como sociedade e como Estado-nacional, como números e como conjunto de hábitos, valores e gestos (DAMATTA, 2004, p.11).

A título de exemplo, DaMatta vê no carnaval brasileiro a reunião dessa leitura complementar entre qualitativo/quantitativo, pois tal rito festivo expressa a ausência das "hierarquias sociais", do poder, do dinheiro e do trabalho cotidiano; é "uma festa onde todos sáo iguais - ou onde podem viver uma significativa experiência de igualdade" (2004, p. 38). Ou seja, é a inversão de uma sociedade administrada pela 'escala de direitos e deveres vindos de cima para baixo, dos superiores para os inferiores'.

\section{BREVE LEITURA DA NOÇÃO DE UM BRASIL MODERNO}

A questão da "modernização" da sociedade brasileira começou a ser estudada por pensadores como Oliveira Vianna (Instituiçôes políticas brasileiras de 1949), Azevedo Amaral (O Estado autoritário e a realidade nacional 1938), Nestor Duarte (A ordem privada e a organizaçâo politica nacional 1939) e Sérgio Buarque de Holanda (em Raízes do Brasil de 1936). De modo geral, estes autores buscavam demonstrar o vínculo entre o passado colonial e as mudanças ocorridas com a industrialização nacional, assim como a nova estruturação das classes sociais e Estado nacional.

Octavio Ianni em $A$ ideia de Brasil Moderno destaca a vida social e política da Independência (1.822) e a Guerra do Paraguai (1.864-70) como indicadores da necessidade de se pensar o Brasil enquanto nação. Já "em 1.888-89 o Brasil tentou entrar no ritmo da história. Aboliu a Escravatura e a Monarquia, proclamando a República e o trabalho livre” (1994, p. 21): incentivando as forças econômicas e políticas interessadas na agricultura, indústria e comércio, além de favorecer a imigração e povoamento do país.

Na segunda metade do século XIX também inicia-se o embate entre a "tradição patriarcal” e o "processo de ocidentalização" por meio da influência europeia burguesa, e não mais portuguesa. Podemos citar como exemplo as mudanças no hábito de vestir-se, da leitura e das refeiçóes desses (tempos modernos', ou seja, "o brasileiro se transveste de 'civilizado', conferindo sentido àquela frase hoje utilizado por todo brasileiro, civilizando-se para inglês ver” (SOUZA, 2000, p. 213).

Sobre isso, DaMatta nos explica que o movimento de Independência exigiu do estrato dominante, legitimar determinada identidade e mecanismos de racionalização para as diferenças internas do país. Dois desses empreendimentos foram fundamentais - afirma: "creio que ela veio na forma da fábula das três raças e no racismo à brasileira” (1987, p. 68), uma ideologia que permitiu conciliar 
uma série de impulsos contraditórios de nossa sociedade sem criar um plano para sua transformação profunda.

Com a abolição do trabalho escravo e a Proclamação da República - de acordo com Ianni (1994, p. 128-9), há uma crescente valorização do imigrante implicando numa proposta social de europeização, isto é, branqueamento da população. Entregue o poder estatal às mãos da oligarquia cafeeira "foi o contexto em que se acentuou a valorização do trabalhador branco, imigrante branco, como agente ou símbolo da redefinição social e cultural do trabalho braçal”.

Assim marcha, timidamente, a Revolução Burguesa no Brasil; momento em que se criara o estigma social do índio, do negro, e até mesmo do trabalhador nacional branco (porém, pobre) como aqueles que se entregavam à luxúria, vícios ou preguiça. Isso levou Florestan Fernandes (1920-1995), - preocupado com essa questão (ver Mudanças sociais no Brasil de 1974 e A revolução burguesa no Brasil de 1975) - a diagnosticar que o negro e o mulato "tiveram o pior ponto de partida" na transição da ordem escravocrata à ordem competitiva-capitalista.

Estudando esse autor, Jessé pontua que "a tese de Florestan é de que a família negra não chega a se constituir como uma unidade capaz de exercer as suas virtualidades principais de modelação da personalidade básica" (2003, p. 156). Acarretando assim, à constatação que "em sociedades periféricas modernizadas de fora para dentro, como a brasileira, 'gente' vai ser o europeu".

Contudo, ao chegar em 1930 - segundo Ianni, o Brasil apruma-se no ritmo de sua história como país contemporâneo do seu tempo: especialmente $1^{\circ}$ ) organizando-se segundo interesses dos setores sociais mais avançados; $2^{\circ}$ ) com surtos de industrialização nacional e urbanização. Para este pesquisador, "os indícios de modernização que já se esboçavam com a Semana de Arte Moderna, a eclosão do tenentismo e outros acontecimentos de anos e décadas anteriores, a partir de 30 parecem acelerar-se" (1994, p. 30).

Em síntese, sobre as matrizes ideológicas que ajudaram a construir a noção de nação brasileira para as ciências sociais, Ortiz destaca: "três tiveram um impacto real junto a intelligentsia brasileira: o positivismo de Comte, o darwinismo social, e o evolucionismo de Spencer" (2006, p. 14); estudos teóricos que interpretam a evolução histórica-social dos povos.

\section{DUAS LEITURAS DISTINTAS SOBRE GILBERTO FREYRE E A FORMAÇÃO DA SOCIEDADE BRASILEIRA}

Gilberto Freyre (Casa Grande \& Senzala 1933), Sérgio Buarque de Holanda (Raizes do Brasil 1936), Caio Prado Jr. (Evolução Política do Brasil 1933), e Raymundo Faoro (Os donos do poder 1958) são autores, entre outros, com obras de leituras obrigatórias para se compreender a historiografia brasileira.

A importância de Casa Grande \& Senzala (1933) é dar conta do que a realidade social das transformações da década de 30 exigiam; onde as teorias "científicas raciológicas" - dominantes nesse contexto, não faziam mais sentido. Freyre, esquivando-se dessas abordagens, direciona o conceito de raça numa perspectiva culturalista - como esclarece Ortiz (2006, p.41):

A passagem do conceito de raça para o de cultura elimina uma série de dificuldades colocadas anteriormente a respeito da herança atávica do mestiço. Ela permite 
ainda um maior distanciamento entre o biológico e o social, o que possibilita uma análise mais rica da sociedade.

Ao problematizar tal obra no livro A modernização seletiva - uma interpretação do dilema brasileiro (2000) Jessé de Souza ressalta que essa passagem permitiu Freyre construir a representação da identidade social do brasileiro e sua virtude cultural - o mito da brasilidade, permitindo-o pensar-se positivamente enquanto povo.

Quando Gilberto Freyre analisa o período histórico-social do Brasil colônia destaca fortemente o aspecto do "patriarcalismo": tema principal de seu estudo, onde náo existiam limites à autoridade pessoal do patriarca senhor de terras, de engenho e de escravos; pelo fato que não havia instituiçóes aqui e o Estado ainda constituía-se em Portugal. "Nesse tipo de concepção de sociedade, a hierarquia é o dado central e cada pessoa, grupo ou classe tem o seu lugar naturalizado" (SOUZA, 2000, p. 212).

Freyre, de certo modo, ao recalcar em sua teoria social o conflito existente entre a relaçáo senhor/escravo na sociedade brasileira construiu uma "imagem idílica” e emblemática influente no imaginário social da nossa colonização; o que chama de "contradições em equilíbrio" sobre tal relação não retrata a brutalidade e perversidade típico dos sistemas escravocratas.

Graças ao fenômeno da "plasticidade do português" (SOUZA, 2000), - categoria importante em Casa Grande \& Senzala - do homem "sem ideais absolutos nem preconceitos inflexíveis" se propiciará a extraordinária influência da cultura negra nos costumes, língua, religiáo e especialmente na forma de sociabilidade entre desiguais: misturando cordialidade, sedução, afeto, inveja, ódio reprimido e praticamente todas as nuances da emoção humana num tipo de "caldeiráo cultural" como explica Darcy Ribeiro (1922-1997) em O povo brasileiro.

Essas "contradiçôes em equilíbrio" - expressão dessa tese culturalista, se justifica pela característica de nosso regime escravocrata antes ser árabe-maometano (devido a absorção cultural dos costumes dos mouros pelos portugueses) que, propriamente europeu com interesses puramente objetivos-econômicos. Isso - para o autor de Casa Grande \& Senzala, permitiu o reconhecimento do escravo nâo como simples máquina de trabalho, mas sim pessoa 'doméstica' quase membro da família. A relação escravocrata amigável-familiar do mouro (povo da região norte da África adeptos do islamismo) "explicaria para Gilberto Freyre o elemento de proximidade e especificidade da escravidáo brasileira como expressão social e cultural singular” (SOUZA, 2000, p. 223).

Essa expressão social e cultural singular da formação social brasileira em Casa Grande \& Senzala, ocorreu pelo fenômeno da "poligamia" que o português incorporou como herança cultural maometana. Os portugueses cá legitimaram no núcleo familiar e social os filhos de mães índias e/ ou escravas negras: assim o filho dessas mães com o senhor europeu poderia, ou seja, "existia a possibilidade real, quer ela fosse atualizada ou não, ser aceito como 'europeizado', no caso de aceitaçáo da fé, dos rituais e dos costumes do pai” (SOUZA, 2000, p. 225). Dessa relaçáo familiar peculiar, criou-se a ascensão social de alguns não-brancos e não-negros.

O tema da ascensão social do negro e sua "europeização" não é objeto de pesquisa em Casa Grande \& Senzala, vai ser, no entanto, um dos fios condutores da argumentação de Sobrados e Mocambos de 1936: obra que consagra a categoria vulgarizada de "democracia racial". Nesse caso, o sobrado será a casa do senhor rural (o patriarca) na cidade; no novo contexto que florescia: a urbanização do final do século XIX.

Cabe mencionar que até o século XX o principal problema nacional-internacional do país (legitimado pela autoridade pseudocientífica) - também aquilo que justificara seu atraso político 
e econômico - diz respeito a forte "miscigenação" do país: onde acreditava-se dividir as "raças" de acordo com três critérios fundamentais: intelecto (inclinação do branco), propensôes animais (inclinação do negro) e moralidade (civilidade do europeu).

Lilia Moritz Schwarcz (1993) nos atenta que o colapso dos paradigmas teóricos incidentes a partir de 1870 cumprindo papel fundamental como "ideário positivo-evolucionista", na "representação negativa do mestiço" (por exemplo: o darwinismo social, o evolucionismo, a frenologia, ideias lombrosianas etc.) se justificou especialmente pelo surgimento de Universidades no país no século XX.

\section{INTERPRETAÇÃO DAMATTIANA}

A concepção científica do carioca Roberto DaMatta baseia-se em pressupostos "pragmático" e "empiricista"; em Relativizando: uma introdução à antropologia social (1987) é claro sua "leitura do mundo social" empreendida a partir de estudos do cotidiano brasileiro, seus rituais e modelos de ação: uma teoria social que investiga a relação "sociedade e sistema cultural" no Brasil.

Para Jessé de Souza (2001) as categorias mais gerais que DaMatta utiliza para analisar a estrutura das sociedades industrial-capitalista - a relação entre "indivíduo" e "pessoa", não contempla a complexidade constitutiva que tais sociedades exigem. Esse dado é fundamental na medida em que todas as outras noçóes damattianas (por exemplo, o sagrado/profano, a casa e a rua) são decorrência desse antagonismo primário, desenvolvido pelo autor ao longo das décadas de 80 e 90 em obras como Carnavais, malandros e heróis (1981), A casa e a rua (1991) e O que faz o brasil, Brasil? (1999).

DaMatta opera analiticamente com tais categorias pelo seu entendimento de duas leituras antagônicas da realidade brasileira (SOUZA, 2001): uma institucional, a qual destaca os macroprocessos políticos e econômicos segundo a lógica da economia política clássica, e outra 2) culturalista, cuja ênfase seria concedida ao elemento cotidiano dos costumes e da tradição familiar. Assim, o autor acredita ter percebido a 'gramática profunda' do universo social brasileiro, quando na verdade - para Jessé, o acesso a essa gramática exigiria a superação desse próprio dualismo.

Para aquele autor, a concepção que denomina 'fábula das raças' ao sustentar a formação de um estrato dominante colonial estimulou a "ausência de valores igualitários" ao lado da patronagem, intimidade e consideração do chefe patriarca. Ao contrário da segregação racial norte-americana, por exemplo, que correspondia à própria realidade daquele país, "onde o credo igualitário, o individualismo e o ideal da igualdade perante a lei criavam obstáculos insuperáveis para uniôes entre pretos e brancos em outros planos que não fosse o do trabalho" (DAMATTA, 1987, p. 77).

Questão que lê-se, inclusive, quando DaMatta escreve na introdução de Sobrados e Mocambos de Gilberto Freyre (2004, p. 15):

Nosso passado patriarcal, tutelar, formado pelas hierarquias das casas grandes e dos sobrados alimentado pelo parasitismo social da escravidão, tem criado muitos obstáculos a certos aspectos da modernidade como o ideal da igualdade perante a lei.

Freyre foi o primeiro a inverter essa "representação negativa" do mestiço ao acentuar que só no Brasil havia a possibilidade do indivíduo superar a condição de negro ou mestiço - meio inexistente, por exemplo nos E.U.A - e "embranquecer-se" em questão de geraçôes numa espécie de "democracia racial". Conforme corrobora DaMatta $(1987$, p. 75$)$ "neste sistema, não há necessidade de segregar o mestiço, o mulato, o índio e o negro, porque as hierarquias asseguram a superioridade do 
branco como grupo dominante.

No capítulo IV - Sabe com quem está falando? Um ensaio sobre a distinção entre indivíduo e pessoa no Brasil da obra Carnavais, Malandros e Heróis, encontra-se uma condensação dos aspectos desenvolvidos na interpretação damattiana da realidade brasileira;

Tudo leva a crer, então, que as relaçôes entre a nossa 'modernidade' - que se faz certamente sob a égide da ideologia igualitária e individualista - e a nossa moralidade (que parece hierarquizante, complementar e holística) são complexas e tendem a operar num jogo circular (DAMATTA, 1997, p. 201).

Aqui o autor pretende ilustrar o desenho hierarquizante da sociedade no qual todo brasileiro se reconhece facilmente: a diferença dessa égide - ideológica, igualitária e individualista, e o aspecto moral que se expressam na distinção conceitual e prática entre "indivíduo" e "pessoa" enquanto relaçôes estruturais que formam a sociedade brasileira.

Para o antropólogo DaMatta, indivíduo é aquele que está submetido às aplicações da instituição jurídica (sem influência da 'carteirada' ou qualquer reconhecimento social distinto); contrariamente, pessoa é a figura de distinto "prestígio e poder social" acima das regras ou leis universais. Nesse entendimento há o indivíduo das relaçôes impessoais (sujeito às leis) e a pessoa das relaçôes sociais de compadrio, amizade e família tradicional.

\section{INTERPRETAÇÃO DE JESSÉ DE SOUZA}

Veremos que a antropologia social de DaMatta é insuficiente enquanto teoria científica na medida em que não deixa evidente o quanto a economia (instituição mercado), mas também o Estado - é um poderoso elemento transformador da vida individual numa espécie de interdependência indivíduo-instituição.

Influenciado por Max Weber (1864-1920), Georg Simmel (1858-1918) e Norbert Elias (18971990) Jessé reitera a importância da (1) estratificação social relacionada à (2) dinâmica valorativa social, e (3) a implicação que as instituiçôes desempenham na conduta de forma racional e emocional sobre os indivíduos. "A dualidade damattiana pressupóe a perda da eficácia específica das instituiçóes que criam o mundo moderno. Os valores são percebidos como tendo existência independente da vida institucional” (SOUZA, 2001, p. 53).

Em uma abordagem que privilegia apenas "indivíduos", "pessoais" ou "espaços sociais", como faz Roberto DaMatta, desconsiderando as questóes de classe ou grupos sociais - torna-se possível referir-se a indivíduos que se contrapóem em lugares distintos; os quais carecem de qualquer "determinação estrutural”. Tal confusão entre esferas públicas e privadas (Casa e Rua, na linguagem damattiana) são características típicas de sociedades tradicionais e patrimoniais pouco diferenciadas; sociedades, portanto, pré-modernas.

Baseando-se nos escritos de Charles Taylor (1931-atualmente), As fontes do self: a construção da identidade contemporânea (1997) e sua hermenêutica da moralidade moderna que analisa a constituição social das hierarquias morais e a questáo do autocontrole, calculo prospectivo e disciplinarizaçáo dos indivíduos: espécie de economia emocional como pré-requisito para o sucesso social no mercado de trabalho, Jessé contra argumenta que "são as normas e regras sociais implícitas que hierarquizam uma sociedade. Indivíduos ou classes dominantes são, no máximo, suportes desses valores e normas, mas de modo algum, sujeitos intencionais desse processo" (2001, p. 54). Ou seja, 
a vida social moderna pressupóe pré-condiçóes racionais, psíquicas e emocionais como "elemento disciplinável" da personalidade dos indivíduos e que servem como 'matéria-prima das burocracias da economia e da política moderna'. Melhor,

A vida social moderna contém, portanto, as duas vertentes da configuraçáo moral ocidental, baseada numa noçáo dúplice de indivíduo: a noção de dignidade generalizável, cujo lugar privilegiado é a economia e o mundo do trabalho, e a noção de autenticidade, que tem no casamento baseado em sentimentos e na constituiçáo de um espaço de intimidade (SOUZA, 2001, p. 55).

A questão principal nesse ponto que o autor quer chamar atenção é a compreensão que indivíduo e pessoa - como sugere o dualismo damattiano, refere-se na realidade, a dimensóes distintas do mesmo entendimento de "indivíduo", e como tais são instrumentos analíticos inadequados dado as condiçôes modernas e complexas.

\section{UMA INTERPRETAÇÃO ALTERNATIVA DO DILEMA BRASILEIRO}

O sociólogo Jessé de Souza entende as mudanças da década de 30 como o início de uma "modernização seletiva" da sociedade brasileira. Para esse autor, a modernização do século XIX com todo choque europeizador - contrário à interpretação damattiana de herança patológica -, desde logo virou de ponta cabeça o personalismo colonial, isto é:

A seletividade do nosso processo de modernização começa aí. $\mathrm{O}$ senhor tem o desafio de, bem ou mal, adaptar-se aos novos tempos. O escravo, esse vai ser abandonado e ficará desprovido de acesso às benesses do novo sistema que se institucionaliza a partir de entáo. Quem ocupa os novos empregos abertos pelo desenvolvimento de manufaturas e maquino faturas é o mulato e depois o europeu imigrante (SOUZA, 2000, p. 265).

Consequentemente, esse processo de modernização no Brasil - para Jessé (2009, p. 21), constituirá uma classe inteira de indivíduos não só sem "capital cultural" como sem "capital econômico" significativo, "mas desprovida, esse é o aspecto fundamental das precondiçôes sociais, morais e culturais que permitem as apropriaçóes de tais capitais".

O paradigma político-econômico do liberalismo-conservador - que o autor critica duramente por "economicismo", dita a percepção ingênua-mercadológica da sociedade ser formada por "agentes racionais que calculam suas chances relativas na luta social por recursos escassos" (2009, p. 17), onde estes possuiriam as mesmas disposiçôes de comportamento e capacidade disciplinar, família estruturada, pensamento prospectivo, capacidade de concentraçáo, 'autocontrole' e 'autoresponsabilidade': além do reducionismo das 'classes sociais' confundidas como produto direto de "renda" econômica.

Jessé adverte em $A$ invisibilidade da desigualdade brasileira (2006) que confundir a implicação secundária do "capital social de relaçóes pessoais" na sociedade moderna brasileira, torna "invisíveis os capitais econômico e cultural (para usar o jargão de Bourdieu), os quais, esses sim, são os elementos estruturais e impessoais e são, portanto, as chaves para a compreensão da hierarquia 
social de toda sociedade moderna” (2006, p. 17), causa real da desigualdade, da marginalidade ou subcidadania da ralé brasileira.

Para o autor, a análise sociológica deve problematizar a produção e reprodução das pré-condiçôes morais, culturais e políticas entre indivíduo e sociedade começando pela instituição familiar e escolar. Indicadores sintomáticos a esse processo histórico de desigualdade social. Apoiado no francês Pierre Bouerdieu (1930-2002) e sua teoria sistêmica do capitalismo Ocidental, Jessé compreende a concentração de poder e privilégios na sociedade brasileira influenciados: tanto pelo capital simbólico (prestígio e reconhecimento social do indivíduo), capital social (as relaçôes sociais), capital econômico (a renda, imóveis, terras) quanto o capital cultural (saber humanístico, artístico e científico) distribuídos desigualmente na luta competitiva por recursos escassos.

Nas análises sociológicas do autor sobre a construção estrutural da modernização brasileira, Jessé opera conceitualmente o capital econômico e cultural sob a teoria do habitus de Bouerdieu: desmistificando a "ideologia da igualdade de oportunidades" do economicismo liberal. Tal noçáo teórica serve para esclarecer a "problemática essencial de toda teoria da ação social que é a questão da coordenação das ações dos indivíduos, ou seja, a questão de como obrigaçóes morais e interesses materiais e ideais influenciam o comportamento" (SOUZA, 2006, p. 18).

Nesse sentido, habitus é um "conjunto de disposiçóes" ligadas a um "estilo de vida peculiar estratificado por classes sociais e que legitimam, de forma invisível e subliminar, o acesso diferencial aos recursos materiais escassos" (2006, p. 34). Ajustando às singularidades da sociedade brasileira, Jessé o reformula por habitus precário: quando considerado a condição de desestruturação familiar e a má-fé institucional dos serviços públicos no Brasil para a ralé.

Para o autor uma análise científica sobre a "cultura do privilégio" e a questão da desigualdade social abarca o entendimento que a "divisão de classes" forma-se pela "transferência de "valores imateriais’ na reprodução das classes sociais e de seus privilégios no tempo" (2009, p. 19). Mesmo as classes altas que detêm o poder econômico, os filhos, por exemplo, só terão a mesma vida privilegiada dos pais se herdarem também o "estilo de vida" - o capital cultural de valor imaterial. Isso nos permite compreender que,

A legitimação do mundo moderno como mundo 'justo' está fundamentada na 'meritocracia', ou seja, na crença de que superamos as barreiras de sangue e nascimento das sociedade pré-modernas e que hoje só se leva em conta o 'desempenho diferencial' dos indivíduos (SOUZA, 2009, p. 22).

O autor procura desconstruir o dilema ideologizado pelo paradigma economicista de "mérito individual", indicando que tal premissa mascara simbolicamente contradiçôes reais de desvantagem social, econômica e cultural na competição de mercado capitalista.

Essa necessidade de desempenho diferencial dos indivíduos está relacionado aos tipos de privilégios produzidos por heranças afetivas no interior das culturas de classes distintas (seja a família da classe alta, média ou baixa) passadas de pais para filhos: seja o simples hábito da convivência dos filhos com o tio fluente noutra língua, a leitura diária do jornal do pai ou da mãe com o romance, ou ainda, o sentimento de autoconfiança por sentir-se amado.

É preciso partir, portanto, literalmente do 'berço', ou seja, da socialização familiar primária, para que se compreenda as classes e sua formação e como elas irão definir todas as chances relativas de cada um de nós na luta social por recursos 
escassos. As classes são reproduzidas no tempo pela família e pela transmissão afetiva de uma dada 'economia emocional' pelos pais aos filhos (SOUZA, 2017, p. 52-3).

Com isso, Jessé de Souza entende que o antropólogo social Roberto DaMatta e sua "sociologia do jeitinho brasileiro ${ }^{4 ”}$ interpreta o Brasil numa perspectiva de país pré-moderno, sua abordagem de "sociedade hierarquizada e determinada pelo particularismo enraizado nas relaçóes interpessoais e na prática institucional do Estado" (2009, p. 73) acaba por reproduzir a mesma "teoria culturalista" iniciada por Gilberto Freyre e defendida por Sérgio Buarque de Holanda (1902-1982) - de "personalismo" (homem cordial) e "patrimonialismo" (privatização da coisa pública) ao estudar a sociedade brasileira; contribuindo negativamente para a percepçáo do senso-comum e acadêmico de "naturalização" do Estado como reino da elite corrupta e divinização do mercado enquanto espaço da plena virtude.

No capítulo A gênese da ciência conservadora dominante no Brasil do livro A ralé brasileira (2009) Jessé registra que Freyre é o grande fundador do paradigma "culturalista científico" nas ciências sócias.

$\mathrm{O}$ argumento teórico de Freyre vai ser todo dirigido à construção de uma "tendência" portuguesa e depois luso-brasileira. Melhor, "se pudemos dizer que Freyre é o pai-fundador da concepção dominante de como o brasileiro se percebe tanto no senso comum quanto na dimensão científica, então Sérgio Buarque é o grande sistematizador das ciências sociais no Brasil do século 20" (SOUZA, 2009, p. 54). Buarque se apropria da ideia de plasticidade como herança ibérica e projeta o conceito de "homem cordial" na sua tese do "personalismo" e do "patrimonialismo" como as marcas fundamentais da cultura brasileira, isto é: o predomínio emocional da ação social sobre o cálculo racional do europeu.

Para Jessé, "o que Buarque chama de personalismo é uma forma de viver em sociedade que enfatiza os vínculos pessoais, como amizade ou ódio pessoal" (2009, p. 55) e que culturalmente nos legou o "homem cordial", aquele que se deixa levar pelo coração, pelos bons ou maus sentimentos que acompanham nossa vida afetiva.

O sistematizador das ciências sociais brasileiras "percebe com clareza que o homem cordial é o homem moldado pela família, em contraposição à esfera da política e da economia que exigem disciplina, distanciamento afetivo e racionalidade instrumental, tudo aquilo que o homem cordial não é" (SOUZA, 2009, p. 55). Por conta disso, o Estado brasileiro passa a ser reconhecido pelo domínio do patrimonialismo (ao amigo tudo ao inimigo a lei): uma gestão da política baseada no interesse particular por oposição ao interesse público.

O capital do homem cordial é o mesmo capital de relaçóes pessoais damattiano, "ou aquilo que Roberto DaMatta, discípulo de Sérgio Buarque como quase todos, chamaria mais tarde de 'jeitinho

4 Essa noção de "jeitinho" é o retrato simpático, muitas vezes desesperado, de relacionar o impessoal com o pessoal do brasileiro na concepçáo de DaMatta, almejando juntar um objetivo pessoal (atraso, falta de dinheiro, ignorância das leis, má vontade do agente da norma ou do usuário, injustiça da própria lei, rigidez das normas etc.) com um obstáculo impessoal. "O 'jeito' é um modo específico e socialmente legítimo de resolver tais problemas provocando uma junção casuística da lei com a pessoa" (2004, p. 48). 
brasileiro', uma suprema bobagem infelizmente naturalizada pela repetição" (SOUZA, 2017, p. 23).

No capítulo 5 - O jeitinho brasileiro da obra A tolice da inteligência brasileira (2015) Jessé de Souza ressalta diretamente que a antropologia social de DaMatta pertence a esse culturalismo cientifico e conservador. Pois,

Seria como se as relaçóes pessoais desempenhassem o papel do Judiciário nos países individualistas e igualitários. Como cabe ao Poder Judiciário precisamente dirimir conflitos a partir dos casos concretos, teríamos, no nosso caso específico, uma resolução informal, sem burocracia e rápida: através da "carteirada", do jeitinho, da ameaça velada e do "você sabe... (SOUZA, 2015, p. 57).

Do mesmo modo que Sérgio Buarque, DaMatta incorpora o personalismo freyriano e entende "o Brasil herdeiro de Portugal no seu personalismo pré-moderno mesmo depois que o país se urbaniza, se moderniza e se industrializa” (SOUZA,2015, p. 53). Assim como Gilberto Freyre exaltava e comparava Brasil e Estados Unidos, o autor de Carnavais, Malandros e Heróis repete o mesmo complexo histórico do vira-lata (síndrome do colonizado acrítico) sugerindo aquele país o exemplo acabado de "igualdade e individualismo".

DaMatta logra operar uma modernização importante no paradigma do personalismo, ao associar a noção de pessoa (basicamente o mesmo homem cordial de Buarque), definida como o agente com acesso a um certo capital social de relaçôes pessoais, à noção de indivíduo definido como o agente sem acesso ao referido capital social de relaçóes pessoais, adaptando a interpretação do personalismo a uma sociedade que já vivia inegável processo de modernização (SOUZA, 2009, p. 59).

Com outras palavras, a sociedade industrial-moderna brasileira não pode ser interpretada estruturalmente pelo "capital social de relaçôes pessoais" (embora isso contribua sem dúvida para alguma chance de sucesso pessoal), pois, tal leitura legitima o tipo de "dominação social" que só identifica "indivíduos" e subtrai a configuração das classes que os formam - onde o "acesso aos capitais 'impessoais' econômico e cultural que se transmite por herança afetivas e intelectuais no interior das famílias das classes privilegiadas" (SOUZA, 2009, p. 77), acaba por ser ideologizado como "esforço próprio".

A consequência - dirá Jessé, dessa leitura estruturalista do capital social de relaçóes pessoais (que reflete apenas indivíduos e espaços sociais) é a pressuposição de "complexos institucionais, como Estado e mercado, como se esses fossem realidades 'externas' aos agentes” (2009, p. 78); quando na verdade dever-se-ia "percebê-los como instituiçôes ambivalentes cujo raio de ação será definido por lutas sociais concretas".

Segundo esse autor, as categorias analíticas de capital econômico e capital cultural são instrumentos chaves para, inclusive a compreensão e interpretação das "hierarquias sociais" presentes na sociedade brasileira. $\mathrm{O}$ esforço de uma interpretaçáo alternativa do dilema brasileiro contra a tradição cientifica dominante, é a superação dessa permanência secular (tanto enraizado nas ciências sociais quanto no senso comum) do personalismo e relaçóes sociais associadas a este - como noçóes de herança ibérica ou patrimonialismo, sendo principais indicadores analíticos para se entender o Brasil. Assim, indaga Souza (2009, p. 79): "ou o leitor conhece alguém que tenha acesso privilegiado 
a pessoas importantes (o capital pessoal ou o ‘jeitinho’ de DaMatta) sem já possuir capital econômico ou capital cultural?"

\section{CONSIDERAÇÕES FINAIS}

Os argumentos apresentados reforçam que a condição de pauperização, organização familiar disfuncional e a construção da personalidade-individual relativiza-se conforme às "situaçôes de classes" e não podem passar despercebidas, muito menos entorpecidas ideologicamente por falsos discursos economicistas, ora quando se pretende analisar realmente a sociedade brasileira e não reproduzir meramente uma perigosa cruzada moralista de corrupção-patrimonialista.

A crítica de Jessé de Souza diz respeito a tradição freyriana científica-culturalista de "glorificação dessa herança pré-moderna, e outra que pretende possuir um 'charminho crítico', como a de Sérgio Buarque, Raimundo Faoro e Roberto DaMatta, apenas porque invertem o sinal e acusam essa mesma tradição de ser nosso mal de origem” (2009, p. 57). É insuficiente teoricamente qualquer interpretação que pretenda explicar tanto a "cultura do privilegio" e a extraordinária desigualdade social a partir do acesso diferencial a certo capital de relaçóes pessoais.

O resultado das contradiçóes da sociedade moderna se expressam na categoria de ralé (ou subcidadania) envolvendo para Jessé a indagação do que é "ser gente" no Brasil; tal noção está ligada à hierarquia determinante da "desigualdade estrutural" brasileira: ideologizada pelo discurso liberal-conservador de "mérito e desempenho individual" e reproduzida diariamente pelos próprios núcleos familiares.

Tais noçôes de ralé ou subcidadania são o resultado estrutural da modernização seletiva da sociedade brasileira. A própria discussão sobre a condição de vida "dessa gente" envolve a questão da formação e reprodução da desigualdade social que hierarquiza classes que têm acesso privilegiado a capitais econômicos e cultural de classe em relação às que não têm.

Por isso partir literalmente do berço, ou seja, da socialização familiar primária, para que se problematize as precondiçóes sociais, morais e culturais e como elas irão definir todas as chances relativas de cada um de nós na luta social por recursos escassos. As classes são reproduzidas no tempo pela família e pela transmissão afetiva de uma dada 'economia emocional' pelos pais aos filhos. Capital cultural que ganha-se, primeiramente por herança familiar e, por conseguinte, pela escola ou universidade pré-dispondo o indivíduo, por exemplo, pelo cultivo e prática da disciplina, autocontrole, cálculo prospectivo enquanto pressupostos psicossociais de socializaçáo determinantes para o "trabalho útil".

Essa classe social compóe cerca de $1 / 3$ da população brasileira abaixo dos princípios de "dignidade e expressivismo" (SOUZA, 2009), condicionada ao mercado informal e ser apenas corpo mal pago e explorado, tornando-se desprezíveis para a sociedade, razão pela qual seus membros carecem de autoconfiança ou estima social.

Da ligeira comparação crítica entre Jessé de Souza e Roberto DaMatta acredita-se de singular importância o entendimento de instituiçôes como Estado, mercado e sociedade civil comporem unidades funcionais de interdependência e de lutas sociais concretas: não instâncias isoladas e dominadas patrimonialmente por "capital social de relaçóes pessoais" como sugere a tradição das ciências sociais dominantes no Brasil. 


\section{REFERÊNCIAS}

DAMATTA, Roberto. Relativizando - uma introdução à antropologia social. Rio de Janeiro, 1987.

O que faz o brasil, Brasil. Rio de Janeiro, 1994.

O que é Brasil. Rio de Janeiro: ROCCO, 2004.

de Janeiro, ROCCO, 1997.

FREYRE, Gilberto. Sobrados e Mocambos - decadência do patriarcado rural e desenvolvimento do urbano. $15^{\circ}$ ed. Global. São Paulo, 2004.

IANNI, Octávio. A ideia de Brasil moderno. São Paulo, Ed. Brasiliense,1994.

SOUZA, Jessé. A modernizaçáo seletiva - uma interpretação do dilema brasileiro. Sáo Paulo, Ed. UnB, 2000.

A ralé brasileira - quem é e como vive. Belo Horizonte, Ed. UFMG, 2009.

A invisibilidade da desigualdade brasileira. Belo Horizonte: Ed. UFMG, 2006.

Ed. LeYa, 2015.

. A tolice da inteligência brasileira: ou como o país se deixa manipular pela elite. São Paulo,

A elite do atraso - da escravidão à lava jato. Rio de Janeiro, Ed. LeYa, 2017.

A sociologia dual de Roberto Da Matta: descobrindo nossos mistérios ou sistematizando nossos auto-enganos? RBCS vol. $16 \mathrm{n}^{\circ}$ 45, fevereiro/2001.

SCHWARCZ, Lilia Moritz. O espetáculo das raças: cientistas, instituiçôes e questão racial no Brasil - 18701930. São Paulo: Companhia das Letras, 1993.

ORTIZ, Renato. Cultura brasileira e identidade nacional. São Paulo, Ed. Brasiliense, 2006. 